\title{
O alcance do direito à identidade pessoal no direito civil brasileiro
}

\author{
The range of the right to a personal identity in brazilian civil law
}

\author{
Carlos Nelson de Paula Konder
}

\section{Resumo}

\begin{abstract}
O artigo aborda a transformação do direito à identidade pessoal, passando de sua versão inicial - conformada por decisões italianas da década de 1970 como defesa contra a imputação de uma identidade que não seja compatível com a sua - para uma versão interdisciplinar - na qual se tutela o próprio processo dinâmico de construção dialógica da identidade, protegendo-o contra a ausência ou insuficiência do seu reconhecimento. São mencionadas questões atuais e controversas envolvendo o direito à identidade, tais como: o direito a não ter sua imagem utilizada fora de contexto, as fake news, a proteção das terras indígenas e quilombolas, o direito ao esquecimento, a tutela da identidade genética e do direito a conhecer as próprias origens, a criação de perfis falsos na rede, a liberdade de orientação sexual e o tratamento jurídico da transexualidade, para então, diante de toda essa abrangência, discutir os limites ao direito à identidade pessoal. Nesse ponto, o artigo refuta a utilização em abstrato do interesse público e discute o critério da proteção da autonomia existencial.
\end{abstract}

Palavras-chave: Dignidade da pessoa humana. Identidade. Interesse público.

\section{Abstract}

The article deals with the transformation of the right to personal identity, going from its initial version, conformed by Italian decisions of the 1970s, as a defense against the imputation of an identity that is not compatible with its own, to an interdisciplinary version in which it protects the very dynamic process of the dialogical construction of identity, defending it against the absence or insufficiency of its recognition. Current and controversial issues involving the right to identity are mentioned, such as the right not to have their image used out of context, fake news, the protection of indigenous lands and quilombolas, the right to oblivion, the protection of genetic identity and the right to know their own origins, the creation of false profiles in the network, the freedom of sexual orientation and the juridical treatment of transsexuality, in order to discuss the limits to the right to personal identity. At this point, the article refutes the abstract use of the public interest and discusses the criterion of the protection of existential autonomy.

Keywords: Human dignity. Identity. Public interest.

\section{Introdução}

A concepção original do chamado direito à identidade pessoal, formulado a partir de decisões judiciais italianas na década de 1970, teve pouca receptividade entre nós, mas o tema hoje ganha destaque no cenário nacional a partir da expansão do seu alcance, despertando grande resistência e controvérsia sobre algumas de suas manifestações. Desde o direito a não ter sua imagem utilizada fora de contexto até a proteção das terras indígenas e quilombolas, da defesa contra a indústria das fake news à liberdade de orientação sexual, da criação de perfis falsos na rede ao direito ao esquecimento no caso de transexualidade, há limites ao direito à identidade pessoal?

Partindo da premissa de que a identidade pessoal é um tema transversal, que corta as separações entre os tradicionais ramos do direito e a arcaica dicotomia entre direito público e direito privado, o

Professor do Departamento de Direito Civil da Faculdade de Direito da Universidade do Estado do Rio de Janeiro (UERJ) e do Departamento de Direito da Pontifícia Universidade Católica do Rio de Janeiro (PUC-Rio). Doutor e mestre em Direito Civil pela UERJ e especialista em Direito Civil pela Universidade de Camerino (Itália). Rio de Janeiro- RJ- Brasil. E-mail: c.konder@gmail.com. 
presente artigo visa discutir o alcance do direito à identidade pessoal. Compreende a identidade pessoal como exemplo da insuscetibilidade das manifestações da dignidade da pessoa humana serem restritas a modelos típicos de proteção, como os direitos da personalidade, ou se aterem ao padrão repressivo, descurando de seu aspecto promocional.

Para isso, o texto se inicia por uma panorâmica apresentação das decisões que the deram origem, compreendendo seus contornos originais, para abordar, em seguida, a profunda transformação que se operou com base em um aprofundamento interdisciplinar sobre a própria construção da identidade. Somente a partir disso serão abordadas suas principais repercussões e, enfim, discutidos os seus limites.

\section{Origens do direito à identidade pessoal}

A primeira referência a um direito à identidade pessoal no âmbito do direito civil costuma ser atribuída a Adriano De Cupis, em sua obra de 1959 sobre direitos da personalidade. Embora já se referisse, naquela época, à necessidade de "ser conhecido por quem é na realidade" e a um "direito à verdade pessoal", sua abordagem ainda era restrita a uma visão estática da identidade, limitada às categorias clássicas dos direitos da personalidade, como o direito ao nome (DE CUPIS, 2004, p. 179-180).

Foi, mais uma vez, a atuação diuturna e incansável da jurisprudência, em sua fecunda atividade de lidar com os novos dramas da realidade, que deu amplitude e concretude ao direito à identidade pessoal, libertando-a dos tradicionais modelos típicos dos direitos da personalidade. Merecem menção as decisões paradigmáticas das cortes italianas durante a década de 1970, minuciosamente descritas por Lígia Fabris Campos em uma das principais obras sobre o tema (CAMPOS, 2006).

Inicia-se pela decisão pioneira do Tribunal de Roma ao analisar o caso do Comitê Nacional para o Referendo do Divórcio, que, em um manifesto a favor da revogação da lei que autorizava o divórcio, se utilizou da imagem de duas pessoas com os dizeres "Para defender a família, os agricultores, em 12 de maio, votarão SIM contra o divórcio". Ocorre que o retrato utilizado, oriundo de um concurso fotográfico realizado dezoito anos antes, apresentava duas pessoas que não somente não eram casadas nem agricultores, como eram, na verdade, co-autores da lei que havia autorizado o divórcio (CAMPOS, 2006, p. 52).

Diante disso, o tribunal atendeu à pretensão deles e determinou a proibição da publicação do manifesto e a divulgação na imprensa, às expensas do Comitê, de um esclarecimento de que a fotografia foi utilizada sem o seu consentimento e não refletia a sua opinião. Em sua fundamentação, afirmava-se que a tutela do direito de todos a ver reconhecida a paternidade dos próprios atos envolve, sobretudo, o de não se ver atribuída a autoria de atos que não são próprios do titular, isto é, a não ver distorcida a própria personalidade individual, especialmente quando envolvendo as convicções políticas, éticas e sociais do indivíduo, por estarem ligadas à esfera mais íntima da personalidade (CAMPOS, 2006, p. 53-54). Portanto, o problema não era a utilização da imagem por si só, mas o contexto em que ela era utilizada, criando uma vinculação da imagem com um significado ideológico incompatível com a identidade dos retratados.

Cinco anos depois, nova decisão em Turim deu sequência ao desenvolvimento do direito à identidade pessoal. Panfletos produzidos pelo Partido Comunista Italiano afirmavam que o político italiano Marco Panella tinha se ligado à posição adotada pelos representantes da chamada Nova República, grupo político de inspiração diversa do seu partido, conduta que o magistrado entendeu que, ainda que a afirmação no panfleto não pudesse ser considerada uma ofensa à honra, era uma desfiguração da sua identidade política (CAMPOS, 2006, p. 55). Afirmou-se que associar o nome daquela pessoa a uma posição política incompatível com aquela à qual ele tinha dedicado toda a sua história não era fato que pudesse ser reconduzido a uma violação à honra, pois isso implicaria afirmar que adotar aquela orientação política era um fato negativo, o que não seria juridicamente admissível em um ordenamento pluralista e democrático.

Cabe ainda mencionar decisão milanesa do ano seguinte. O renomado oncologista Umberto Veronesi deu uma entrevista na qual divulgava resultados de estudos científicos que relacionavam o hábito de fumar 
com o desenvolvimento de tumores malignos. Ao ser perguntado sobre se todos os cigarros geravam o mesmo risco, respondeu que algumas marcas, mais leves, geravam risco menor, cerca de metade do risco gerado por marcas de teor mais cancerígeno (CAMPOS, 2006, p. 90). Uma das marcas reputadas mais leves pelo médico transformou isso numa publicidade em que afirmava que, segundo o Prof. Umberto Veronesi, diretor do Instituto do Câncer de Milão, fumar o cigarro da marca que ela comercializava reduz quase à metade o risco de câncer (CAMPOS, 2006, p. 91). O Tribunal entendeu que a utilização descontextualizada e parcial da declaração implicava uma distorção da sua personalidade profissional, "um atentado contra sua notória seriedade científica publicamente projetada no tempo" (CAMPOS, 2006, p. 91).

Pode-se afirmar que essas decisões, em realidade, deram origem ao direito à identidade pessoal. Os ricos estudos doutrinários que as analisaram nas décadas que se seguiram, entre os quais se destacam as obras de Carlos Fernández Sessarego (1992) e Giorgio Pino (2003), serviram mais a sistematizar tais decisões, discutindo a autonomia da identidade pessoal e colocando em xeque a organização tradicional dos direitos da personalidade. De fato, o apego excessivo às categorias consolidadas de tutela da personalidade fez com que diversos casos similares no ordenamento brasileiro - em que a categoria da identidade pessoal tardou a se difundir - fossem reconduzidos a figuras como o direito à imagem ou o direito à honra, a partir de alargamentos dessas categorias.

A expansão do direito à imagem favoreceu essa possibilidade à medida em que passou a abranger não somente características fisionômicas do indivíduo (imagem-retrato), mas também seus atributos identificáveis em suas relações sociais (imagem-atributo), ou seja, "o conjunto de particularidades comportamentais que distinguem uma pessoa das outras, podendo, tais particularidades, abonar ou desprestigiar o respectivo indivíduo." (SOUZA, 2003, p. 42). Assim, no contexto da violação da maneira pela qual o sujeito se apresenta à sociedade em que se insere, a fronteira entre o que seja sua imagem e o que seja sua identidade torna-se bastante nublada. Exemplificativo da nebulosidade dessa fronteira foi o caso da atriz Maitê Proença, que pretendeu indenização da farmacêutica Schering por ter feito publicidade para produto anticoncepcional da ré que se revelou ineficaz por defeito de fabricação ("pílulas de farinha"), prejudicando a credibilidade de sua apresentação social junto ao seu público. A questão foi endereçada exclusivamente sobre se houve ou não violação à sua imagem-atributo. ${ }^{1}$

Na mesma linha, a tutela da honra, deitando raízes na visão sexista e patriarcal da honra familiar e da honestidade feminina, é ressignificada como manifestação da dignidade da pessoa humana, tornandose pretensão de respeitabilidade do indivíduo perante a esfera social de que faz parte (REIS JR., 2013, p. 23). Novamente, a aviltação da forma como o sujeito é reconhecido pelo seu círculo social pode ser reconduzida tanto a essa nova leitura da honra como à nova figura da identidade pessoal. Aqui é ilustrativo da zona de penumbra o caso do jogador Edmundo, que acionou a revista Veja pela capa que apresentava foto sua com a manchete "animais no volante", ilustrando reportagem sobre acidente de trânsito em que ele se envolvera. A discussão no processo envolvia a justificação da manchete com base na maneira pela qual o jogador era conhecido pelo público, em virtude de sua agressividade nos campos. ${ }^{2}$

Sob uma perspectiva mais dogmática, é possível identificar e delimitar as áreas de interseção entre essas categorias e as zonas exclusivas de cada uma, reconhecendo-lhes espaço próprio de atuação que Ihe justifique a autonomia. Entretanto, parece que o mais importante no pioneirismo daquelas decisões italianas foi reconhecer uma manifestação da personalidade humana que era merecedora de tutela independente de recondução aos modelos típicos preexistentes.

Aqui, novamente, a categoria dos chamados direitos da personalidade acabou por limitar mais do que expandir a tutela da pessoa humana, encarcerando-a em categorias típicas e submetendo-a ao

BRASIL. STJ. $3^{\text {a }}$ T., REsp 578.777, Rel. Min. Castro Filho, Rel. p/ acórdão Min. Humberto Gomes de Barros, julg. 24.08.2004.

BRASIL. STJ. $3^{a}$ T., Resp 1.201.688, Rel. Min. Massami Uyeda, Rel. p/ acórdão Min. Sidnei Benetti, julg. 23.06.2009. Sobre o julgado, v. MORAES, 2011, p. 597-614. 
modelo patrimonialista dos direitos subjetivos. Cumpre estabelecer a premissa fundamental de que estão fadados ao fracasso os esforços de encarcerar em modelos típicos a proteção da dignidade da pessoa humana, já que ela se transforma e se renova com as transformações da sociedade em que a pessoa se insere. A personalidade, concebida como valor e não como direito, "está na base de uma série aberta de situações existenciais, nas quais se traduz a sua incessante exigência mutável de tutela" (PERLINGIERI, 2008 , p. 764). Nesse sentido, a dignidade da pessoa humana, para além de princípio, configura-se em cláusula geral, apta a abarcar uma infinidade de formas de proteção e promoção do sujeito (TEPEDINO, 2008, p. 54).

Aquela concepção original do direito à identidade pessoal, portanto, ainda que em alguns casos reconduzível a um direito à imagem ampliado (imagem-atributo), ou a um direito à honra ressignificado (honra-respeito), justifica sua autonomia como manifestação da incessante capacidade da personalidade humana se exteriorizar no ambiente social, bem como da também incessante necessidade de protegê-la e promovê-la nesse meio. De fato, os casos abordados pelas decisões italianas continuam atuais mesmo após quase meio século e proliferam-se para além do seu ordenamento de origem, dando lugar a novas categorias de tutela jurídica da identidade.

Assim como os dois italianos coautores da lei do divórcio se viram ofendidos ao verem sua imagem associada a uma campanha a favor do fim do divórcio, há alguns anos a modelo e atriz Luma de Oliveira se viu surpreendida com a utilização de seu retrato fantasiada dançando no carnaval carioca para ilustrar uma matéria veiculada no jornal inglês The Independent referente a um escândalo que envolvia a associação de homens públicos e da montadora Volkswagen com prostituição (CAMPOS, 2006, p. 145). Fala-se, nesse sentido, de um direito a não ter sua imagem utilizada fora de contexto (false light), já que o contexto é um dos critérios que conferem legitimidade ao uso da imagem alheia sem autorização do titular (ALMEIDA JR., 2013, p. 167).

Da mesma forma que Marco Panella foi lesionado por sua associação indevida à corrente Nova República, em tempos de fake news, ou "pós-verdade", não foram raras as informações inverídicas sobre posições de candidatos nas eleições que circularam na rede, como resultado não apenas da capilaridade da internet, mas também de uma indústria profissional de fabricação de boatos movida por interesses econômicos. Nesse tipo de conduta, prejudica-se não só a identidade pessoal do candidato, mas o acesso democrático ao genuíno debate de posições, bem como a legitimidade do processo eleitoral, afirmandose, com nova força, um direito à verdade (BARBOSA, 2017).

Enfim, tal qual o Dr. Umberto Veronesi foi profissional e pessoalmente aviltado pela publicidade tabagista que fez uso do seu nome, o também oncologista Dr. Drauzio Varela foi atingido pela divulgação de uma posição falsa no sentido de que ele seria favorável à política de internação compulsória de dependentes químicos durante as medidas recentemente tomadas pela prefeitura de São Paulo, orientação que ele sempre combateu. Mais uma vez, a conduta atinge não somente a identidade pessoal da vítima, mas o acesso a informações confiáveis de saúde pública, tendo em vista o crescente movimento de busca desse tipo de esclarecimento pela internet (SILVA FILHO et al., 2017).

Esse rápido panorama revela a importância que o reconhecimento do direito à identidade pessoal no nosso ordenamento jurídico continua a ter, mesmo sob essa acepção original. No entanto, esse direito viria a sofrer um salto significativo no seu alcance a partir de uma compreensão mais profunda sobre o significado da identidade pessoal nas relações sociais, como se passa a abordar.

\section{Transformações do direito à identidade pessoal}

A partir dessa versão original, marcada por um viés individual próprio do direito privado tradicional, o direito à identidade pessoal ganhou novas projeções e possibilidades graças a uma reflexão interdisciplinar. De fato, quando se trabalha com um tema como a identidade pessoal, é imprescindível recorrer aos desenvolvimentos científicos da psicologia, da antropologia e da sociologia, e ainda, dentro do direito, 
aos estudos da filosofia do direito, do direito constitucional e, claro, do direito civil. Como destaca Cláudia Carvalho (1999, p. 727-728), o termo "identidade" faz parte do vocabulário teórico de quase todas as ciências, desde a lógica e a matemática até as ciências ditas humanas - identidade pessoal, identidade cultural e identidade nacional - razão pela qual "as interrogações que o estudo da identidade coloca, não podem ser respondidas no âmbito exclusivo de uma só teoria/ciência". Assim, a compreensão do direito à identidade só é viável por meio de uma perspectiva ampliada e interdisciplinar (CHOERI, 2010, p. 72).

Com base nessa perspectiva ampliada, constata-se que a identidade se forma no diálogo com o outro e que, portanto, o direito à identidade pessoal se constrói simultaneamente individual e coletivamente (CHOERI, 2010, p. 166). Dessa forma, a tutela da identidade pessoal não pode restringir-se à leitura de sua construção de forma estritamente isolada, tomando o sujeito como átomo, sob pena de, novamente, restringir a tutela da dignidade da pessoa humana a aspectos limitados de manifestação da personalidade. $\mathrm{O}$ direito à identidade pessoal deve dar guarida à construção coletiva e dialógica das identidades, protegendo o próprio processo pelo qual as identidades se constroem intersubjetivamente.

A construção da identidade envolve, primordialmente, a liberdade para fazer suas próprias escolhas de valores. Charles Taylor explica que a identidade é definida pelos compromissos e identificações que determinam, caso a caso, o que o sujeito considera que é bom ou valioso, o que deve fazer, aquilo que endossa ou a que se opõe, enfim, como ele se coloca no mundo (TAYLOR, 1997, p. 43-44). Essa construção da identidade - "aquilo que nos permite definir o que é e o que não é importante para nós" (TAYLOR, 1997, p. 47) - depende, de forma crucial, das relações do sujeito com os demais (TAYLOR, 1993, p. 55), ou seja, cada um elege os valores, atributos, características e preferências que o tornam ele mesmo a partir do diálogo com os demais sujeitos, e só é possível elaborar uma identidade com referências às demais identidades que a cercam (TAYLOR, 1997, p. 53).

Nesse contexto, recuperando os exemplos iniciais, as identidades dos coautores da lei do divórcio, do político Marco Panella e do médico Umberto Veronesi, bem como da atriz Luma de Oliveira, dos candidatos vítimas de fake news e do dr. Drauzio Varella, devem ser tuteladas não apenas como resultado final, estático, de atributos pessoais, mas como o próprio processo dinâmico de sua construção dialógica com os outros. Novamente, explica Taylor (1997, p. 69-70): "a pergunta sobre nossa condição nunca pode ser esgotada para nós por aquilo que somos, porque estamos também mudando e nos tornando o tempo todo".

Assim, ao direito à identidade pessoal corresponde, invariavelmente, o direito ao reconhecimento dessa identidade que, quando inexistente ou defeituoso, implica claramente uma lesão à dignidade da pessoa humana. O tema do reconhecimento tornou-se central no debate sobre a tutela jurídica das identidades à medida que se constatou que ela envolve essencialmente a possibilidade de sua livre construção dialógica e, mais do que isso, a aceitação coletiva da pluralidade de identidades. Nas palavras de Daniel Sarmento (2016, p. 241):

O olhar do outro nos constitui. O que somos, o que fazemos, a forma como nos sentimos, nosso bem-estar ou sofrimento, a nossa autonomia ou subordinação, tudo isso depende profundamente da maneira como somos enxergados nas relações que travamos com os outros. Quando a sociedade nos trata sistematicamente como inferiores, internalizamos uma imagem negativa de nós mesmos e passamos a moldar as nossas escolhas e ações a partir dela.

Dessa forma, o aprofundamento na compreensão do que seja a construção da identidade implica também a ampliação de sua tutela: protege-se o sujeito não apenas contra a imputação de uma identidade que não seja compatível com a sua, mas igualmente contra a ausência ou insuficiência do reconhecimento de sua identidade. Na medida em que a identidade se molda pelo reconhecimento do outro, a falta dele ou o falso reconhecimento configura um verdadeiro dano, uma autêntica lesão ao direito à identidade pessoal (TAYLOR, 1993, p. 43). Isso importa, então, violação ao princípio da dignidade da pessoa humana também no aspecto da isonomia: "o não reconhecimento significa subordinação social no sentido de ser privado de participar como igual na vida” (FRASER, 2007, p. 107). 
Entre as diversas vertentes teóricas acerca do direito ao reconhecimento em um contexto multicultural, o próprio debate traz o mérito de destacar que assegurar o direito à identidade pessoal envolve exigir do ordenamento não apenas uma atuação repressiva, mas o exercício da função promocional do direito, no sentido de permitir a todos, individual e coletivamente, a construção, o exercício e o reconhecimento de suas próprias identidades. Novamente, a dignidade da pessoa humana manifesta-se aqui como uma cláusula geral que não se limita a reprimir lesões a situações-tipo, em técnica repressiva e ressarcitória, mas atua especialmente em função promocional, fazendo uso dos diversos instrumentos jurídicos para a promoção da personalidade (TEPEDINO, 2008, p. 52).

Sob essa perspectiva, exemplificativamente, pode-se mencionar a reserva dos territórios indígenas e quilombolas projetada pelo constituinte como manifestação de uma atuação promocional da identidade, já que a terra, naquele contexto, funciona como repositório principal de uma identidade construída histórica e coletivamente. A hipótese reconduz à categoria dos "bens culturais", elencados pelo artigo 216 da Constituição como "as formas de expressão; os modos de criar, fazer e viver; as criações científicas, artísticas e tecnológicas; e as obras, objetos, documentos, edificações e demais espaços destinados às manifestações artístico-culturais" quando "individualmente e ou em conjunto, portadores de referência à identidade, à ação, à memória dos diferentes grupos formadores da sociedade brasileira". Esses bens culturais são protegidos como instrumentais à promoção do direito à identidade cultural partilhada por aquela comunidade (MIRANDA, 2016, p. 17-18).

A tecnologia também trouxe novo impulso expansivo à identidade pessoal, já que, como destacou de forma geral Stefano Rodotà (1997, p. 5), se a filosofia foi salva pela ética, o direito privado foi salvo pela tecnologia. Especificamente quanto ao tema da identidade, o autor destaca como a tecnologia permitiu a dissociação do corpo físico e do corpo eletrônico, a multiplicação de identidades pelo próprio interessado, e o "furto de identidade", relatando a experiência de Sherry Turkle, que abriu um fórum de discussão na internet sob um pseudônimo, para não ser reconhecida como autoridade no assunto, até que se viu contestada por um dos usuários, que, para legitimar seus argumentos, se apresentava como sendo a própria Sherry Turkle (RODOTÀ, 2009, p. 76).

De fato, o ambiente virtual das redes sociais ressignificou a identidade, com uma nova miríade de possibilidades e desafios. Em um meio no qual toda informação divulgada se torna disponível não só para a humanidade, como para a eternidade, ganhou renovada importância o chamado "direito ao esquecimento". O impacto de um direito dessa natureza nas liberdades comunicativas tem gerado grande resistência ao seu reconhecimento no ordenamento jurídico brasileiro (EHRHARDT JR. et al., 2017, p. 76-77). Entretanto, sua afirmação não envolve atribuir ao arbítrio do sujeito a prerrogativa de apagar informações que Ihe sejam desagradáveis, mas afastar os danos decorrentes da imputação de características que não mais correspondem à sua identidade. Nesse sentido, para além das controvérsias que o cercam, a referência a "um direito a não ser constantemente perseguido por fatos do passado, que já não mais refletem a identidade atual daquela pessoa", na expressão de Anderson Schreiber (2017), nos lembra a importância de garantir não apenas o direito a construir a própria identidade, mas também de reconstruí-la, já que a identidade é dinâmica e mutável.

A tecnologia desbrava ainda outras fronteiras para a identidade pessoal quando se aventura no âmbito do chamado biodireito. Por exemplo, o direito a conhecer as próprias origens, reputado essencial para que a pessoa possa efetivamente se autoconhecer e autocompreender, já reconhecido na esfera de adoção, é colocado em xeque pelos procedimentos de reprodução assistida heteróloga, isto é, com material genético de doador anônimo. Trata-se da identidade genética, central à compreensão da individualidade biológica do sujeito a partir de sua ascendência, e parte do que se poderia referir como "bioconstituição" (SPAREMBERGER; THIESEN, 2010, p. 63). ${ }^{3}$ 
Em linha similar, os mecanismos de manipulação genética embrionária e, no seu extremo, a clonagem, vulneram o direito à identidade pessoal em sua acepção mais ampla, à medida que transformam características corporais, normalmente oriundas do acaso, em escolhas pessoais de seus genitores. Não se pode menosprezar o impacto que essa escolha teria sobre a autocompreensão moral do sujeito, visto que as características e limitações do seu corpo biológico, que condicionam seu direito de seguir escolhas de vida individuais, não são produto de um fato natural ou de uma circunstância contingente, "impedindo-a de se compreender livremente como o autor único de sua própria vida" (HABERMAS, 2010, p. 87).

Seguramente, contudo, a crista da onda da identidade pessoal no mundo contemporâneo se encontra no âmbito da sexualidade. A partir da fragmentação do conceito de sexo - genético, endócrino, morfológico - a sua qualificação jurídica (também dita civil ou legal) torna-se produto de uma escolha relacionada à sua vida civil, às suas relações em sociedade (CHOERI, 2004, p. 46-51). Cinde-se, assim, o sexo e o gênero, traduzindo este o resultado das vivências culturais e sociais do indivíduo e, portanto, aspecto de sua identidade dinâmica (CORBO; DANTAS, 2014, p. 56). Desse modo, a identidade de gênero apresenta-se segundo uma perspectiva de pertencimento, demandando adequado reconhecimento por parte do Estado (CUNHA, 2015, p. 37-52).

Nesse sentido, o reconhecimento jurídico e social da liberdade para a construção da própria identidade sexual pode ser indicado como a maior conquista das últimas décadas no que tange à efetivação de uma autonomia existencial relativa ao direito à identidade. Como todo movimento de transformação profunda envolvendo tabus e preconceitos historicamente arraigados, faz aflorar dos becos mais escuros forças de resistência e obscurantismo, razão pela qual ainda há um longo caminho a percorrer, mas não se pode deixar de admitir as enormes conquistas do reconhecimento de um direito à identidade nesta seara.

Entre todas as fundamentais demandas relativas à diversidade sexual, provavelmente a transexualidade seja o maior exemplo da ampliação do direito à identidade pessoal. ${ }^{4}$ Já em 1998, Gustavo Tepedino chamava atenção para o tema, relatando o caso de Juracy, transexual que, depois de fazer a cirurgia no exterior, constituir família e adotar uma criança, foi presa no retorno ao Brasil por falsidade ideológica, uso de documento falso e ato destinado ao envio de criança para o exterior, sendo recolhida à ala masculina do presídio de Água Santa, onde ficou detida até a decisão da $1^{\mathrm{a}}$ Turma do TRF da $2^{\mathrm{a}}$ região (TEPEDINO, 2008, p. 71-72)..$^{5} \mathrm{~A}$ jurisprudência que avaliava os pedidos de retificação de registro era guiada pela afirmação de uma verdade do sexo biológico contra o direito à identidade pessoal. ${ }^{6}$ As alterações registrais se deram a duras custas, levando à patologização da transexualidade, transformando a cirurgia em "cura" exigida para autorizar o reconhecimento jurídico da nova identidade. ${ }^{7}$

Paulatinamente, o cenário foi se transformando e foi se admitindo tanto a alteração do nome quanto do sexo registral. A questão chegou aos tribunais superiores, onde a primeira decisão do STJ, datada de 2007, exigia a averbação da mudança, carregada da visão de que a publicidade da mudança era o ônus de uma escolha que não poderia ser escondida ou esquecida. ${ }^{8}$ Contudo, apenas dois anos depois, julgado pioneiro relatado pela ministra Nancy Andrighi autorizava a alteração, com retificação do registro, sob o fundamento de que "afirmar a dignidade humana significa para cada um manifestar sua verdadeira

\footnotetext{
Para uma abordagem da questão por meio especificamente do direito ao esquecimento, cf. MOREIRA; ALVES, 2015, p. 81-102, e CASTRO; ALMEIDA, 2017, p. 65-96.

TRF-2, $1^{\mathrm{a}}$ T., ACR 92.02.18299-0, Rel. Juíza Tania Heine, julg. 08.03.1993.

6 Por exemplo, "Registro civil de nascimento. Nome. Retificação. Mudança do sexo. Impossibilidade. Retificação no Registro Civil. Mudança de nome e de sexo. Impossibilidade. [...] Se o requerente ostenta aparência feminina, incompatível com a sua condição de homem, haverá de assumir as consequências, porque a opção foi dele. [...] Quem nasce homem ou mulher, morre como nasceu. Genitália similar não é autêntica. Autêntico é o homem ser do sexo masculino e a mulher do feminino, a toda evidência" (TJRJ, 8ª C.C., Ap. Civ. 1993.001.06617, Rel. Des. Geraldo Batista, julg. 18.03.1997).

Para argumentos contra a despatologização, cf. Silvestre e Louro (2016).

8 "Mudança de sexo. Averbação no registro civil. 1. O recorrido quis seguir o seu destino, e agente de sua vontade livre procurou alterar no seu registro civil a sua opção, cercada do necessário acompanhamento médico e de intervenção que lhe provocou a alteração da natureza gerada. [...] Esconder a vontade de quem a manifestou livremente é que seria preconceito, discriminação, opróbrio, desonra, indignidade com aquele que escolheu o seu caminhar no trânsito fugaz da vida e na permanente luz do espírito. 2. Recurso especial conhecido e provido" (BRASIL. STJ, $3^{a}$ T., REsp 678933, Rel. Min. Carlos Alberto Menezes Direito, julg. 22/03/2007, publ.DJ 21.05.2007).
} 
identidade, o que inclui o reconhecimento da real identidade sexual, em respeito à pessoa humana como valor absoluto". 9

Desde então, a jurisprudência vem evoluindo a passos largos, admitindo inclusive a retificação do registro independente de cirurgia, em reconhecimento de que a tutela da identidade deve-se pautar não apenas pelo corpo, mas pela maneira pela qual a pessoa se apresenta socialmente; como, aliás, determina a legislação que tutela a utilização do chamado "nome social". ${ }^{10} \mathrm{O}$ tema hoje alcança o Supremo Tribunal Federal, em sede de repercussão geral, tanto no que tange à retificação do registro como no que diz respeito à utilização dos banheiros. ${ }^{11}$

\section{Até onde vai o direito à identidade pessoal?}

O significativo processo de transformação do direito à identidade pessoal - que mais do que uma ampliação, pode ser compreendido mesmo como uma ressignificação - coloca em foco o questionamento sobre o seu alcance. Ao operar um corte transversal entre as tradicionais categorias dos direitos da personalidade e se contrapor, em muitos casos concretos, a diversos interesses constitucionalmente tutelados, grande resistência se coloca a toda essa abrangência atribuída à proteção da identidade pessoal. Em lugar de ceder a qualquer tipo de misoneísmo, que rechace em abstrato a própria expansão dessa categoria, cumpre investigar se existem limites a esse processo.

Partindo do pressuposto de que a identidade pessoal é um direito fundamental, por ser manifestação da dignidade da pessoa humana, do livre desenvolvimento da personalidade e da autonomia existencial, não é possível entender que ela, para ser tutelada, deva atender a alguma função, já que as situações jurídicas existenciais são, em si mesmas, a própria função: a dignidade da pessoa humana preconiza, fundamentalmente, a não instrumentalização do sujeito ao atingimento de outros fins. Portanto, a tutela da identidade pessoal não está condicionada ao limite interno de atingir certo fim: qualquer limite a ele deve se originar diretamente da mesma dignidade da pessoa humana que lhe dá fundamento, em um processo de ponderação.

Isto serve, para, de plano, rechaçar o argumento falacioso, que persiste na nossa cultura jurídica, de encontrar um limite para o chamado "interesse público". O interesse público jamais será limite a ser ponderado com a identidade, com o esquecimento, ou com qualquer outro direito fundamental. Determinar se certo interesse é público ou não, relevante ou não, merecedor de tutela ou não, é sempre o resultado da ponderação, e não sua premissa. A relevância coletiva de certo interesse, assim como sua primazia, só pode ser averiguada em concreto, ante o exame minucioso das circunstâncias do caso. Afirma-se, contemporaneamente:

[...] a definição do que é interesse público, e de sua propalada supremacia sobre os interesses particulares, deixa de estar ao inteiro arbítrio do administrador, passando a depender de juízos de ponderação proporcional entre os direitos fundamentais e outros valores e interesses metaindividuais constitucionalmente consagrados. (BINENBOJM, 2007, p. 749).

Um interesse individual pode também ser "público" a partir do momento que se constate que ele deve ser protegido para qualquer pessoa que se encontre naquela mesma situação. A identidade pessoal pode ser - e frequentemente será - um interesse público, ou seja, o interesse da coletividade de que a todos seja assegurada a tutela da identidade pessoal. Portanto, afirmar em abstrato o interesse público como limite à identidade pessoal é um desserviço à sua análise científica.

9 "Direito civil. Recurso especial. Transexual submetido à cirurgia de redesignação sexual. Alteração do prenome e designativo de sexo. Princípio da dignidade da pessoa humana. [...] - Em última análise, afirmar a dignidade humana significa para cada um manifestar sua verdadeira identidade, o que inclui o reconhecimento da real identidade sexual, em respeito à pessoa humana como valor absoluto. [...] E a alteração do designativo de sexo, no registro civil, bem como do prenome do operado, é tão importante quanto a adequação cirúrgica, porquanto é desta um desdobramento, uma decorrência lógica que o Direito deve assegurar" (BRASIL. STJ. $3^{\mathrm{a}}$ T., REsp 1008398, Rel. Ministra Nancy Andrighi, julg. em 15.10.2009, publ. DJe 18.11.2009).

10 Para exames quantitativo das decisões, cf. Corbo; Dantas, (2014) e Silvestre; Louro (2016).

11 BRASIL. STF. RE 845779 RG, Rel. Min. Roberto Barroso, julg. 13/11/2014; STF, RE 670422 RG, Rel. Min. Dias Toffoli, julg. 11/09/2014. 
Isso, não significa, todavia, que o direito à identidade pessoal não possa colidir, em concreto, com outros interesses que venham, ao final, se revelar públicos, relevantes, merecedores de tutela, ou simplesmente mais aptos à tutela da pessoa humana. Um caso ilustra bem essa situação.

Ganhou a mídia a história de Sandra Duchesneau e Candy McCullough, duas americanas surdas de nascimento que, depois de abordarem diversos bancos de sêmen sem sucesso, conseguiram seu desejo de obter sêmen de um doador também surdo para aumentar as chances de que seu filho tivesse a mesma condição. As duas têm agora dois filhos, Jennifer e Gauvin, ambos com grave deficiência auditiva, e sustentam que a surdez não é uma deficiência, mas uma identidade cultural (MORAES; KONDER, 2012, p. 95-96). O caso não é único: foi noticiado na mídia que também Tomato Lichy e Paula Garfield, britânicos, dedicam-se à mesma empreitada para ter um filho surdo (ATKINSON, 2018).

Nesse caso, a ponderação pode colocar em xeque a invocação do direito à identidade pelos casais. É necessário levar em conta que, no caso concreto, ainda que a qualificação jurídica das deficiências tenha sofrido uma releitura, essa condição, em lugar de produto de uma fatalidade do acaso, seria resultante de uma escolha pessoal dos genitores no caso em exame. O direito à identidade pessoal, que encontra guarida na autonomia existencial, está sendo invocado para submeter alguém a uma identidade predeterminada. $A$ identidade serviria a limitar a pessoa, no aspecto sensorial, e a limitação seria heterônoma, ou seja, uma identidade imposta.

Esse é sempre um ponto delicado em um contexto multicultural, mas talvez seja possível levar em conta - se não como um limite, ao menos como um parâmetro -, que o direito à identidade pessoal destinase primordialmente a assegurar uma esfera de liberdade e, portanto, se for imposto exteriormente, essa circunstância deve pesar negativamente na ponderação. Assim, quando a invocação é feita pelos pais para a configuração da identidade dos filhos, o argumento é mais sensível.

Não se trata, é importante destacar, de privar crianças e adolescentes do acesso a esse direito. $O$ reconhecimento cada vez maior de espaços de autonomia, ainda que assistida, aos menores tradicionalmente incapazes, se faz acompanhar também da construção de uma identidade pessoal; conduzida, é claro, pelo melhor interesse da criança, como é exemplo a cada vez mais debatida transexualidade infantil. Cumpre, contudo, levar em conta a personalidade ainda em formação para não confundir o exercício autêntico da autonomia com a suscetibilidade a pressões externas. Novamente, somente as circunstâncias do caso permitem um juízo adequado.

\section{Conclusão}

O direito à identidade pessoal revela-se, dessa forma, como grande exemplo da impossibilidade de tipificar ou delimitar as formas de manifestação da personalidade merecedoras de proteção. Seu nascimento se dá a partir de decisões judiciais que identificavam a antijuridicidade de imputar a alguém orientações ou características incompatíveis com a forma pela qual ela se apresenta socialmente, ainda que não reconduzíveis a lesões à imagem ou à honra, como tradicionalmente concebidas. Ilustra, portanto, a conveniência de se conceber a dignidade da pessoa humana como uma cláusula geral de tutela da personalidade, apta a abranger sob sua proteção as mais diversas manifestações de seu livre desenvolvimento.

Esse aspecto ressalta a transformação operada pela constatação do aspecto dialógico e coletivo de construção da identidade, no qual o sujeito escolhe suas preferências a partir da relação e contraposição com os demais integrantes do ambiente social em que se insere. Afirma-se, assim, o papel fundamental do adequado reconhecimento das identidades pessoais, a ser promovido especialmente pelo Estado. Novamente, a tutela da identidade pessoal destaca a afirmação da dignidade da pessoa humana como uma cláusula geral, pois eis que ressalta o seu papel não estritamente repressivo, mas também promocional, de favorecer o reconhecimento das identidades pessoais nas diversas formas e contextos de suas manifestações. 
Diante de todo esse processo expansivo, objeto de profundas resistências, cumpre discutir o seu alcance: há limites ao direito à identidade pessoal? De plano, descarta-se qualquer afirmativa de um limite geral abstrato, como a invocação do interesse público. A jusfundamentalidade da identidade pessoal faz com que somente possa ser limitada em concreto, ante a ponderação com outros direitos fundamentais. $O$ que se pode construir são somente critérios e parâmetros para levar em conta no processo.

\section{Referências}

ALMEIDA JR., Vítor de Azevedo. A imagem fora de contexto: o uso de imagens de arquivo. In: SCHREIBER, Anderson (Coord.). Direito e mídia. São Paulo: Atlas, 2013. p. 158-183.

ATKINSON, Rebecca. 'I hoped our baby would be deaf'. The guardian. Disponível em: <https://goo.gl/ ZfQxVY>. Acesso em: 23 jan. 2018.

BARACHO, José Alfredo de Oliveira. A identidade genética do ser humano. Bioconstituição: bioética e direito. Revista de direito constitucional e internacional, São Paulo, v. 32, p. 88-92, jul./set. 2000.

BARBOSA, Hélio Augusto de Lima. O direito à verdade em tempos de pós-verdade. Revista internacional de direito constitucional, São Paulo, v. 1, p. 1-8, jan./mar. 2017.

BINENBOJM, Gustavo. A constitucionalização do direito administrativo no Brasil: um inventário de avanços e retrocessos. In: SOUZA NETO, Cláudio Pereira de; SARMENTO, Daniel (Coord.). A constitucionalização do direito. Rio de Janeiro: Lumen Juris, 2007. p. 743-780.

CAMPOS, Ligia Fabris. O direito de ser si mesmo: a tutela da identidade pessoal no ordenamento jurídico brasileiro. 374 f. 2006. Dissertação (Mestrado em Direito) - Departamento de Direito, PUC-Rio, 2006. Disponível em: <https://goo.gl/XcR6y6>. Acesso em: 19 jan. 2018.

CARVALHO, Cláudia Constante. Identidade e intimidade: um percurso histórico dos conceitos psicológicos. Análise psicológica, Lisboa, v. XVII, n. 4, p. 727-741, 1999. Disponível em: <https://goo.gl/ AoXoS4>. Acesso em: 21 jan. 2018.

CASTRO, Thamis Ávila Dalsenter Viveiros de; ALMEIDA, Vitor. O direito ao esquecimento da pessoa transexual. In: TEPEDINO, Gustavo; TEIXEIRA, Ana Carolina Brochado; ALMEIDA, Vitor (Coord.). Da dogmática à efetividade do direito civil. Belo Horizonte: Fórum, 2017. p. 65-96.

CHOERI, Raul Cleber da Silva. $\mathbf{O}$ conceito de identidade e a redesignação sexual. Rio de Janeiro: Renovar, 2004.

CHOERI, Raul Cleber da Silva. $\mathbf{O}$ direito à identidade na perspectiva civil-constitucional. Rio de Janeiro: Renovar, 2010.

CORBO, Wallace; DANTAS, Alexandre. O direito à alteração registral de transexuais não submetidos à cirurgia de transgenitalização e a jurisprudência fluminense. Revista dos Tribunais Rio de Janeiro, São Paulo, v. 6, p. 55-71, jul./ago. 2014.

CUNHA, Leandro Reinaldo da. Identidade de gênero e a responsabilidade civil do Estado pela leniência legislativa. Revista dos Tribunais, São Paulo, v. 962, p. 37-52, dez. 2015.

DE CUPIS, Adriano. Os direitos da personalidade. Campinas: Romana, 2004.

EHRHARDT JR., Marcos Augusto de Albuquerque; NUNES, Danyelle Rodrigues de Melo; PORTO, Uly de Carvalho Rocha. Direito ao esquecimento segundo o STJ e sua incompatibilidade com o sistema constitucional brasileiro. Revista de Informação Legislativa - RIL, Brasília, ano 54, n. 213, p. 63-80, jan./mar. 2017. Disponível em: <https://goo.gl/Xg409F>. Acesso em: 21 jan. 2018.

FRASER, Nancy. Reconhecimento sem ética? Lua Nova: Revista de Cultura e Política, São Paulo, n. 70, p. 101-138, 2007. Disponível em: <https://goo.gl/Tr3VFm>. Acesso em: 21 jan. 2018.

GEDIEL, J. A. P.; MILANO, G. B. Igualdade racial e territórios tradicionalmente ocupados por quilombolas. In: GEDIEL, José Antônio Peres; SILVA, Eduardo Faria; TRAUCZYNSKI, Silvia Cristina. (Org.). Igualdade racial e territórios tradicionalmente ocupados por quilombolas. Curitiba: Positivo, 2014. p. 1-432. 
HABERMAS, Jürgen. O futuro da natureza humana. Trad. Karina Jannini. 2. ed. São Paulo: Martins Fontes, 2010.

MIRANDA, Jorge. Notas sobre cultura, Constituição e direitos culturais. O Direito, Lisboa, ano 138, n. IV, 2006. Disponível em: <https://goo.gl/zm81kY>. Acesso em: 21 jan. 2018.

MORAES, Maria Celina Bodin de. Honra, liberdade de expressão e ponderação. In: TEPEDINO, Gustavo; FRAZÃO Ana (Coord.). O Superior Tribunal de Justiça e a reconstrução do direito privado. São Paulo: Revista dos tribunais, 2011. p. 597-614.

MORAES, Maria Celina Bodin de; KONDER, Carlos Nelson. Dilemas de direito civil-constitucional: casos e decisões. Rio de Janeiro: Renovar, 2012.

MOREIRA, Rodrigo Pereira; ALVES, Rubens Valtecides. Direito ao esquecimento e o livre desenvolvimento da personalidade da pessoa transexual. Revista de direito privado, São Paulo, v. 64, p. 81-102, out./dez.2015.

NASCIMENTO, Vanderlei de Freitas; LEHFELD, Lucas de Souza. O tratamento social igualitário destinado aos transexuais enquanto expressão dos direitos fundamentais. Revista de direito constitucional e internacional, São Paulo, v. 95, p. 83-102, abr./jul. 2016.

PERLINGIERI, Pietro. O direito civil na legalidade constitucional. Rio de Janeiro: Renovar, 2008.

PINO, Giorgio. II diritto all'identità personale: interpretazione costituzionale e creatività giurisprudenziale. Bologn: II Mulino, 2003.

PINO, Giorgio. L'identità personale. In: RODOTÀ, S.; TALLACCHINI, M. (Coord.). Trattato di biodiritto Ambito e fonti del biodiritto. Milano: Giuffrè, 2010. v. I. p. 297-321.

REIS JÚNIOR, Antonio dos. Novas perspectivas sobre o direito à honra: estudos sob a ótica civilconstitucional. Civilistica.com, Rio de Janeiro, ano. 2, n. 3, jul./set. 2013. Disponível em: <https://goo. gl/8B5nyU>. Acesso em: 19 jan. 2018.

RODOTÀ, Stefano. La vita e le regole: tra diritto e non diritto. Milano: Feltrinelli, 2009.

RODOTÀ, Stefano. Lo specchio di Stendhal. Riflessioni sulle riflessioni dei privatisti. Rivista critica del diritto privato, Napoli, v. 15, p. 5-18, 1997.

SARMENTO, Daniel. Dignidade da pessoa humana: conteúdo, trajetórias e metodologia. 2. ed. Belo Horizonte: Fórum, 2016.

SCHREIBER, Anderson. Nossa ordem jurídica não admite proprietários de passado. Revista consultor jurídico, São Paulo. 12 jun. 2017. Disponível em: <https://goo.gl/4SBtJi>. Acesso em: 21 jan. 2018.

SESSAREGO, Carlos Fernández. Derecho a la identidad personal. Buenos Aires: Astrea, 1992.

SILVA FILHO, Rubens da Costa; SILVA, Leila Morás; LUCE, Bruno. Impacto da pós-verdade em fontes de informação para a saúde. Revista brasileira de biblioteconomia e documentação - RBBD, São Paulo, v. 13, p. 271-287, 2017.

SILVESTRE, Gilberto Fachetti; LOURO, Arthur Souza. A tutela jurídica da identidade do transexual. Revista de direito privado, São Paulo, v. 65, p. 97-117, jan./mar. 2016.

SOUZA, Carlos Affonso Pereira de. Contornos atuais do direito à imagem. Revista trimestral de direito civil, Rio de Janeiro, v. 13, p. 33-71, jan./mar. 2003.

SPAREMBERGER, Raquel Fabiana Lopes; THIESEN, Adriane Berlesi. O direito de saber a nossa história: identidade genética e dignidade humana na concepção da bioconstituição. Revista direitos fundamentais e democracia, Curitiba, v. 7, n. 7, p. 33-65, jan./jun. 2010.

TAYLOR, Charles. La política del reconocimiento. Multiculturalismo y la política del reconocimiento. Madrid: Fondo económico de Cultura, 1993.

TAYLOR, Charles. As fontes do self: a construção da identidade moderna. São Paulo: Loyola, 1997. TEPEDINO, Gustavo. Temas de direito civil. Rio de Janeiro: Renovar, 2008. t. I.

Recebido em: 06/02/2018

Aprovado em: 15/02/2018 